\title{
Field survey and numerical modelling of cracking in masonry walls due to thermal movements of an overlying slab ${ }^{* *}$
}

\author{
K.G.S. Dilrukshi and W.P.S. Dias* \\ Department of Civil Engineering, Faculty of Engineering, University of Moratuwa, Katubedda.
}

\begin{abstract}
Concrete slabs exposed to direct sunlight experience temperature related horizontal movements. In addition, temperatures on the top surface will be higher than those on the underside of the slab, causing an upward deflection of the slab during heating. In a typical building, masonry and concrete elements are connected to each other at their respective interfaces. Therefore, significant movements may be generated on the masonry walls due to the movement of the roof slab. These movements can result in overstressing and cracking in masonry. These cracks may not be structurally serious, but may lead to ingress of moisture and in any case are not acceptable especially where good finish is desired.
\end{abstract}

In this study, the behaviour of these cracks was predicted based on surveys of buildings where cracks have formed. Also, typical structural arrangements were mathematically modelled using 3D brick finite element models, with link elements between the masonry and concrete elements in order to model interfaces. The objective of the study was to investigate the stresses developing on the wall due to the movement of the roof slab. Locations and directions where cracking would occur were identified using the principal stresses developed in the finite element model and a failure criterion developed based on the modified Von-Mises theory. Also, using these numerical models, the effect of wall length and structural form of the wall (i.e. load bearing walls and reinforced concrete framed walls) on the formation of these cracks was studied. These results were compared with the information obtained from the survey.

Keywords: Masonry concrete interface, masonry walls, numerical modelling, thermal cracking, thermal movements

\section{INTRODUCTION}

Cracking is the most common and visible defect found in masonry. Most buildings crack at some time during their service life. The appearance of a crack is a symptom of distress within the fabric of a building. Cracking in brittle materials such as masonry are caused by internal stresses building up until they exceed the rupture strength of the material. Once the rupture strength is exceeded the crack develops and internal stresses are dissipated. These stresses are generally caused by the movements of the building due to uneven foundation settlements, temperature changes, shrinkage due to moisture changes, chemical processes or creep deformations of materials.

The appearance of cracks can affect the value of the building, its insurability and saleability, and can initiate litigation. Cracking must also be controlled to maintain the moisture resistance of the wall. Even though non structural cracking of masonry is not a normal structural design consideration, regardless of the reason for cracking, it is unacceptable where good finish is desired. Therefore, studying these cracks and factors causing them is important in order to propose remedial measures.

Sri Lanka is a tropical country with long hours of sunshine. Therefore, temperature induced cracks are common on masonry walls. Thermal stresses can develop due to direct thermal radiation on a wall or due to the differential movements caused by thermal variations of different parts of the structure.

Concrete slabs exposed to direct sunlight experience temperature related horizontal movements. In addition, temperatures on the top surface will be higher than those on the underside of the slab, causing an upward movement of the slab during heating (Figure 1). In a typical building, masonry and concrete structural elements are connected to each other at their respective interfaces. Therefore,

\footnotetext{
* Corresponding author

${ }^{* *}$ Part of this work was presented at the $12^{\text {th }}$ Annual Symposium of the Engineering Research Unit, University of Moratuwa in November 2006.
} 


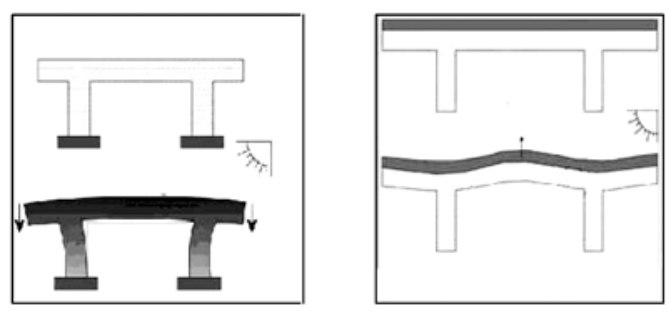

Figure 1: Upward movement of slab during heating

significant movements may be generated in the masonry walls, due to the movement of the roof slab. These movements can result in overstressing and cracking in masonry.

The main objective of this ongoing study is to understand the relative importance of factors that cause cracking, such as the structural form of wall (i.e. whether the wall is load bearing or within a concrete frame), aspect ratio of wall and the effect of different geometric and structural conditions (e.g. presence of openings, lintels etc.). This was done by using a three pronged approach, through a survey of cracking in buildings, physical modelling, and numerical modelling. This paper presents the details regarding the building survey and the preliminary results of numerical modelling.

Due to the vast array of different geometrical configurations and boundary conditions of masonry walls, the use of experimental methods for understanding stress development due to different loadings and movements is costly and difficult. As a result, the use of the Finite Element Method (FEM) is resorted to.

The FEM has been extensively used in analysis of masonry structures and numerous models have been developed to simulate the behaviour of different types of conventional masonry systems. The necessity of preserving historical constructions and the need for a better understanding of the mechanical behaviour of structural masonry has led to great innovations in the development of specific numerical techniques for analysing such constructions. Numerical models of course need to be calibrated against or compared with physical models or full scale structures.

Masonry is a composite, heterogeneous, non-linear material that exhibits distinct directional properties because the mortar joints act as planes of weakness. Many efforts have been made to model this complicated nature of masonry. Three modelling techniques have been used to model structural masonry ${ }^{1}$, with different approaches to recognise its inherent discontinuous nature (units, joints and interfaces). (a) Detailed micro modelling: Units and mortar in the joints are represented as continua, whereas the unit/mortar interfaces are modelled by dis-continuum elements.

(b) Simplified micro modelling: Geometrically expanded continuum units are used with dis-continuum elements covering the combined behaviour of both mortar joints and interfaces.

(c) Macro modelling: Here, all three principal components of structural masonry are represented by an equivalent continuum.

The use of micro modelling procedures runs into practical difficulties in the case of masonry because each brick and joint will have to be described as separate elements. This restricts the use of this method to small test problems and is the main reason why the finite element method has been used by various researchers ${ }^{2-4}$ only for restricted geometries. When analysing large and real structures, use of macro modelling is more convenient and gives more benefits because less parameters are involved. Various researchers ${ }^{4-8}$ have attempted to solve complex problems using this technique.

An interface is a special contact plane of which the stresses or strains may not be continuous and it has become a focus of numerical analysis. In engineering practice there are varieties of structures with interfaces. Composite materials and structural and geological media interfaces are common phenomena in engineering.

An interface may be treated as either a completely bonded interface or an incompletely bonded interface ${ }^{9}$. The completely bonded interface should prevent relative displacements from occurring at the contact plane while the incompletely bonded interfaces (used in this study) may have the behaviours of sliding, de-bonding, rebonding and rotation.

In the context of the finite element method, there are two major groups of interface elements/models ${ }^{10}$ known as the "zero thickness" interface element and "thin layer" interface elements. Various types of joint or interface elements have been developed to date by many investigators to represent interface joint behaviour. Athensis $^{11}$ has conducted a detailed study about techniques for modeling interfaces in discontinuous systems. He shows that the explicit representation of discontinuities by means of FEM and so called interface elements goes back to work of Goodman et al. in 1973, Zienkewicz et al. in 1970 and Gaboussi et al. in 1973. According to the Rots ${ }^{3}$ the method was first developed and applied to solid masonry by A.W. Page in 1988 . 
Ibraham $^{5}$ has modeled the concrete-masonry interface using a thin layer interface element to study effect of temperature changes on the performance of masonry buildings.

Masonry is a complex material where response to mechanical loads is highly complex. The strength of masonry in compression, tension and shear has been the subject of systematic investigation over a very considerable period. Two approaches have been adopted as the basis of failure theories ${ }^{12}$. The first assumes uniaxial elastic behaviour (based on the maximum principal stress) and the second relates the behaviour of the unit and joint material under the action of bi-axial or tri-axial stress. A number of investigators have attempted to derive failure criteria for masonry using experimental and theoretical methods.

Previous studies ${ }^{13,14}$ have established failure surfaces for brickwork stressed in orthogonal tension-compression by the application of normal stresses to small specimens of brick masonry, in which the bed joint was inclined at various angles to the axis of application.

An analytical mathematical model describing the masonry failure surface in a simple manner is an effective tool for investigating the behaviour of masonry structures. Many analytical criteria for masonry structures have already been proposed. The modified Mohr-Coulomb failure criterion ${ }^{3,15}$, Rankine type failure criterion $^{15}$ and modified Von Mises criterion ${ }^{16,17}$ are popular among them.

\section{METHODS AND MATERIALS}

Survey of buildings: Details about the structural form of buildings were collected, such as whether it was load bearing, concrete framed or a combination. The

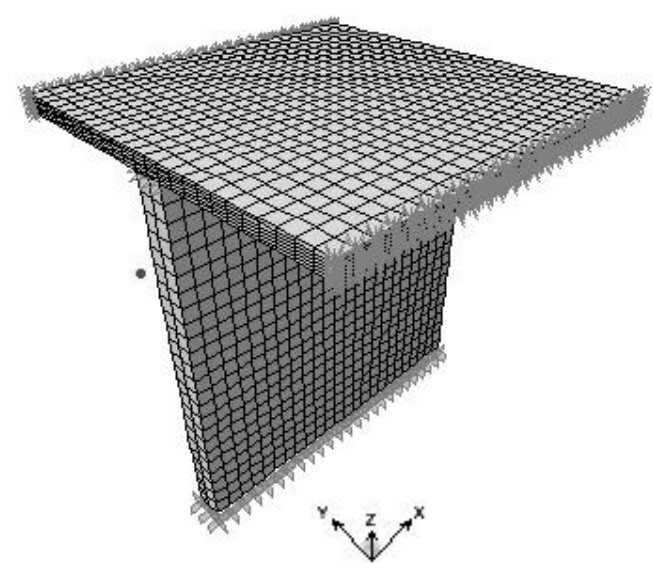

Figure 2: Part of building considered for the analysis orientation of the building with respect to the North and ratio of building length to width were obtained. The date or time after construction at which cracks had appeared was noticed and the nature of the cracks was ascertained - i.e whether they increased monolithically with time or whether their widths were cyclic with diurnal temperature variation. The latter is good evidence for the cracks being thermal, as opposed to settlement cracks. Care was taken to eliminate settlement as a cause for cracks, as we wished to focus on thermal cracking. However, in many cases shrinkage cracks were also present with thermal cracks. The most common type of shrinkage crack is where infill masonry walls separate away from the concrete frame. In load bearing walls, a prominent vertical crack through the height of the wall will be a shrinkage crack.

The location and orientation of cracks were observed in order to identify the pattern of cracking. Depending on the shape of the cracks they were categorized as horizontal cracks, diagonal cracks, and vertical cracks. These details were marked on sketches of the relevant elevations. To understand the pattern of formation of these cracks, all the details taken from the above sketches were marked on a plan of the building.

Numerical modelling of solid walls: In this study a typical wall connected to the effective slab area was considered separately, rather than analysing a whole building. The idealised part considered for the analysis is shown in Figure 2.

To model the continuity of the roof slab, translation in the direction perpendicular to the plane of the wall was restrained. In order to find stresses developed in walls with respect to the structural form of building and the aspect ratio of the wall, the following models (Table 1) were considered for the analysis. The height and thickness of every wall was $3 \mathrm{~m}$ and $225 \mathrm{~mm}$ respectively. The effective slab area was (length of wall $\times 3$ ) $\mathrm{m}$ and the thickness $125 \mathrm{~mm}$.

Table 1: Details of models considered for the study

\begin{tabular}{|c|c|c|c|c|}
\hline \multirow[b]{2}{*}{ Model } & \multicolumn{2}{|c|}{ Structure type } & \multirow[b]{2}{*}{ Length (m) } & \multirow{2}{*}{$\begin{array}{l}\text { Distance } \\
\text { between } \\
\text { columns (m) }\end{array}$} \\
\hline & $\begin{array}{c}\text { Load } \\
\text { bearing }\end{array}$ & $\begin{array}{c}\text { Concrete } \\
\text { framed }\end{array}$ & & \\
\hline M1 & $\sqrt{ }$ & & $3 m$ & - \\
\hline M2 & & $\sqrt{ }$ & $3 \mathrm{~m}$ & $3 m$ \\
\hline M3 & $\sqrt{ }$ & & $6 \mathrm{~m}$ & - \\
\hline M4 & & $\sqrt{ }$ & $6 \mathrm{~m}$ & $3 \mathrm{~m}$ \\
\hline M5 & & $\sqrt{ }$ & $6 \mathrm{~m}$ & $6 \mathrm{~m}$ \\
\hline M6 & $\sqrt{ }$ & & $9 \mathrm{~m}$ & - \\
\hline M7 & & $\sqrt{ }$ & $9 \mathrm{~m}$ & $3 \mathrm{~m}$ \\
\hline M8 & & $\sqrt{ }$ & $9 \mathrm{~m}$ & $4.5 \mathrm{~m}$ \\
\hline
\end{tabular}


Both concrete and masonry were considered as homogeneous and isotropic materials. Rather than modelling bricks and joints separately, masonry was modelled as one constituent - i.e. using the macro modelling approach.

Solid elements were used to model both masonry and concrete elements. In SAP 2000 the solid element is an eight node element for modelling three dimensional structures. Each solid element has its own local coordinate system for defining material properties and loads and interpreting output.

Concrete and masonry elements were considered as continuum elements and the concrete-masonry interface was considered as a discontinuum. Therefore, in this study special attention was paid to the modelling of the concrete-masonry interface. The interface was modelled using a zero thickness interface element. In SAP 2000 either a single joint or two joint link element with distance between two nodes less than or equal to the zero-length tolerance (which was set to $1 \mathrm{~mm}$ ) was considered as a zero length joint element. For this study, both axial and shear deformations of the two joint link element between concrete and masonry were considered.

The method developed by Rots ${ }^{3}$ to model the masonry-mortar interface was used in this study to model the concrete-masonry interface. The constitutive behaviour of the unit is described by stress-strain relations for the continuum element. In the linear elastic stage, the stress $(\sigma)$ and strain $(\epsilon)$ relationship can be described according to Hooke's law. For the analysis in the joint interface of concrete and masonry, the presence of a $10 \mathrm{~mm}$ thick mortar layer was assumed. The situation is illustrated in Figure 3.

Case 1 (Figure 3a) shows the actual situation with adhesive areas on both sides of the mortar layer. In
Case 2 (Figure 3b) a compound interface has been created, accounting for both adhesion areas and the mortar layer. Finally, in Case 3 (Figure 3c) the concrete and masonry units were "blown up" to create an interface with zero thickness but with the properties of the adhesion areamortar layer-adhesion area combination.

The total lengthening across half the units and joint should be equal in both Case 2 (over a length $l$ ) and Case 3 (over a length $l^{\prime}$ )

\section{For Case 2}

$$
\Delta \ell=\sigma\left[\frac{h_{c}}{2 E_{c}}+\frac{h_{j}}{E_{j}}+\frac{h_{m}}{2 E_{m}}\right]
$$

Where $h_{c}, h_{m}, h_{j}$, are the thicknesses and $E_{c}, E_{m}, E_{j}$ are the moduli of elasticity of the concrete, masonry and joint respectively.

For Case 3 (the simplified model)

$$
\Delta \ell^{\prime}=\sigma\left[\frac{h_{c}^{\prime}}{2 E_{c}^{\prime}}+\frac{1}{k_{n}}+\frac{h^{\prime}{ }_{m}}{2 E^{\prime}{ }_{m}}\right]
$$

However, $\Delta \ell$ should be equal to $\Delta l^{\prime}$

We have also assumed that blown up units have the same E value as the real units (i.e $E_{c}=E_{c}^{\prime}$ and $E_{m}=E_{m}{ }^{\prime}$ )

Also, $\quad h_{m}^{\prime}=h_{m}+\frac{h_{j}}{2} \quad$ and $\quad h_{c}^{\prime}=h_{c}+\frac{h_{j}}{2}$

Therefore the normal stiffness of the interface element will become

$$
k_{n}=\frac{4 E_{c} E_{j} E_{m}}{h_{j}\left(4 E_{c} E_{m}-E_{m} E_{j}-E_{c} E_{j}\right)}
$$

Similarly the shear stiffness of the interface element wil be

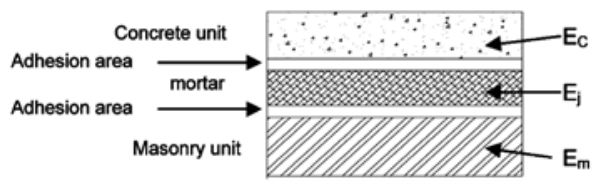

(a) Case 1

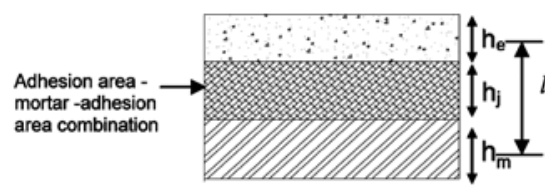

(b) Case 2

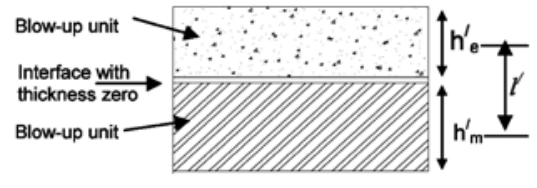

(c) Case 3

Figure 3: Concrete - masonry interface modelling 


$$
k_{t}=\frac{4 G_{c} G_{j} G_{m}}{h_{j}\left(4 G_{c} G_{m}-G_{m} G_{j}-G_{c} G_{j}\right)} \text { Where } G=\frac{E}{2(1+\gamma)}
$$

Two major loads were applied to the structure. The first is the self load of structural element and the second is the temperature variation of the roof slab. The slab was divided into six equal layers having temperatures of $68^{\circ} \mathrm{C}, 60^{\circ} \mathrm{C}, 53^{\circ} \mathrm{C}, 47^{\circ} \mathrm{C}, 42^{\circ} \mathrm{C}, 38^{\circ} \mathrm{C}$ from top to bottom. This is based on the shape of thermal gradients in slabs reported in the literature. The reference temperature of the materials (and therefore the temperature of the masonry) was considered as $35^{\circ} \mathrm{C}$.

The mechanical and thermal properties of the materials used in this study are summarised in Table 2. Properties used for concrete are default values of SAP 2000 and properties of masonry are based on work done by Jayasinghe ${ }^{17}$ on Sri Lankan brick masonry.

In this study the possibility of cracking at the concrete-

Table 2: Material Properties

\begin{tabular}{lcc}
\hline & Concrete & Masonry \\
\hline Weight per unit volume & $23.6 \mathrm{kN} / \mathrm{m}^{3}$ & $20.0 \mathrm{kN} / \mathrm{m}^{3}$ \\
Modulus of elasticity & $25.0 \mathrm{E} 6 \mathrm{kN} / \mathrm{m}^{2}$ & $1.0 \mathrm{E} 6 \mathrm{kN} / \mathrm{m}^{2}$ \\
Poisson's ratio & 0.2 & 0.2 \\
Coeff. of thermal expansion & $9.9 \mathrm{E}-6 /{ }^{\circ} \mathrm{C}$ & $6.0 \mathrm{E}-6 /{ }^{\circ} \mathrm{C}$
\end{tabular}

masonry interface and cracking within the masonry walls were considered separately. The initiation of interface cracking was modelled by means of a Mohr-Coulomb yield criterion combined with tension cut off criterion ${ }^{3}$ (Figure 4). Since tensile cracking is the most important nonlinearity that governs the behaviour of materials like masonry, the model was used to simulate initiation of fracture under combined normal and shear stresses in the tension shear region (tensile and shear strength of the masonry-concrete interface joint was assumed as equal to the tensile and shear strength of masonry which is equal to $0.2 \mathrm{~N} / \mathrm{mm}^{2}$ and $0.13 \mathrm{~N} / \mathrm{mm}^{2}$ respectively). Since the model is three dimensional and the failure criteria is two dimensional, the resultant shear stress in the horizontal plane with the normal tensile stress in vertical plane was considered for the analysis.

A failure criterion developed based on modified Von Mises theory ${ }^{18}$ was used to check the possibility of cracking of masonry walls. The failure envelope is formed by the interaction of four surfaces $\mathrm{S}_{1}, \mathrm{~S}_{2}, \mathrm{~S}_{3}$ and $\mathrm{S}_{4}$ as illustrated in Figure 5. The surfaces are described by the equations as follows:

$\mathrm{S}_{1}$ - represents a compression stress state parallel to both principal axes.

$\mathrm{S}_{1}:{\sigma_{1}}^{2}+{\sigma_{2}}^{2}+\sigma_{1} \sigma_{2}+3 \tau^{2}-{f_{w c}}^{2}=0$ for $\sigma_{1}$ and $\sigma_{2} \leq 0$

$\mathrm{S}_{2}$ - represents a stress state of compression parallel to one principal axis and tension parallel to the other.

$\mathrm{S}_{2}: \sigma_{2}+\left(1-\sigma_{1} / a\right) \sqrt{{f_{w_{c}}{ }^{2}-3 \tau^{2}}^{2}}=0$ for $\sigma_{1} \geq 0$ and $\sigma_{2} \leq 0$

Where $a=\left(f_{w t} / f_{w c}\right) \sqrt{f_{w c}^{2}-3 \tau^{2}}$

$\mathrm{S}_{3}$ - represents a tensile stress state parallel to both principal axes.

$\mathrm{S}_{3}: \sigma_{1}+\sigma_{2}-\alpha=0 \quad$ for $\sigma_{1}$ and $\sigma_{2} \geq 0$

$\mathrm{S}_{4}$ - symmetrical to $\mathrm{S}_{2}$ in respect to the bisectional level of the first quadrant

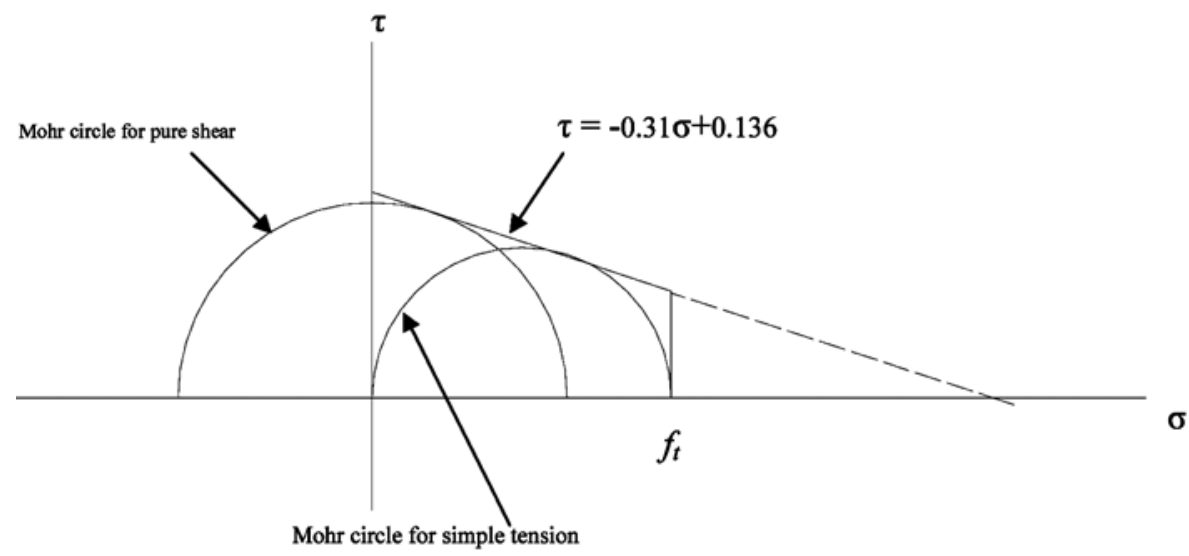

Figure 4: Mohr - Coulomb yield criterion combined with tension cut off criterion 


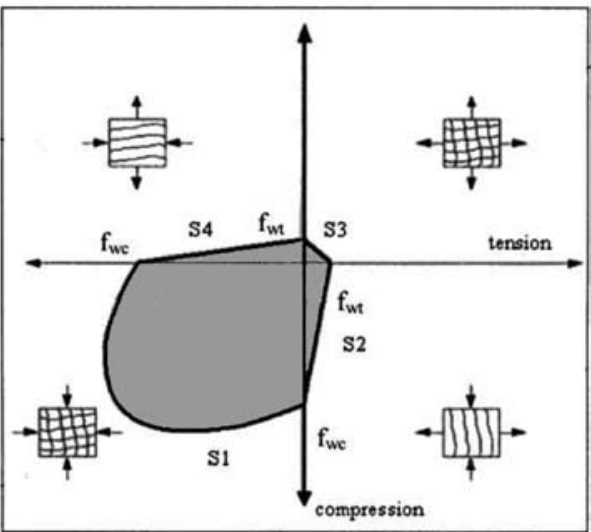

Figure 5: Modified Von - Mises failure criterion for masonry

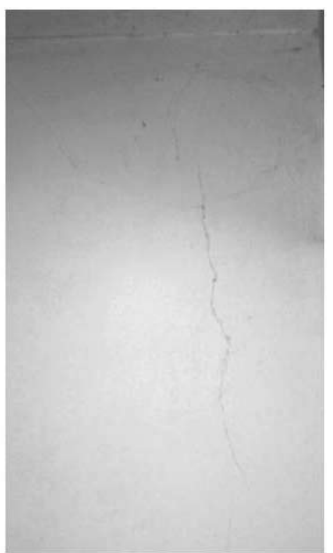

Figure 7: Vertical crack at the centre part of a load bearing wall

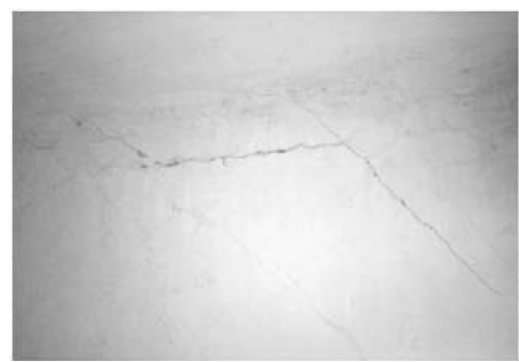

Figure 9: Diagonal crack at the outer edges of load bearing wall

Also (from ref. ${ }^{17}$ )

$f_{\text {wc }}$ : Compressive strength of masonry (taken as $2 \mathrm{~N} / \mathrm{mm}^{2}$ )

$f_{\mathrm{wt}}$ : Tensile strength of masonry (taken as $0.2 \mathrm{~N} / \mathrm{mm}^{2}$ )

$\tau$ : Shear strength of masonry (taken as $0.13 \mathrm{~N} / \mathrm{mm}^{2}$ )

This criterion considers the bi-axial failure of

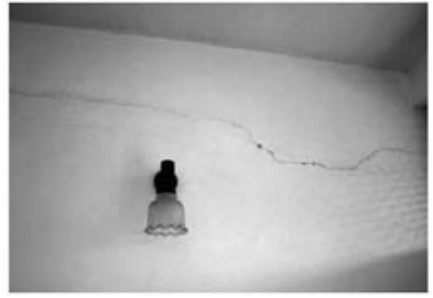

Figure 6: Horizontal cracking under beams

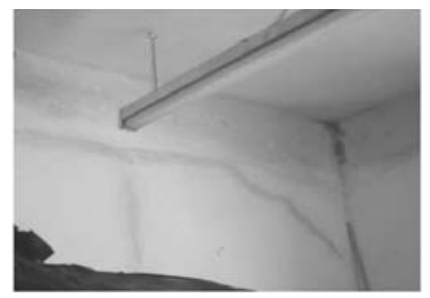

Figure 8: Diagonal crack at the outer edges of concrete framed wall
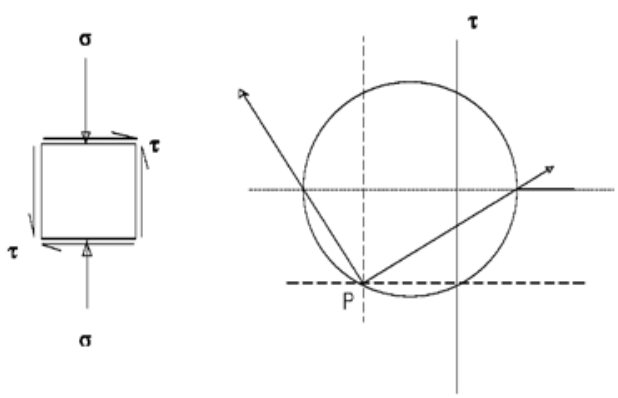

Figure 10: Mohr circle representation of stresses of a load bearing masonry element

masonry based on principal stresses. Since our model is three dimensional, three principal stresses are produced, each one corresponding to the relevant principal axis. Therefore, for the failure analysis two principal stresses (maximum and minimum principal stresses $\sigma_{1}$ and $\sigma_{2}$ respectively) were considered, with the influence of the third (mid principal stress $\sigma_{3}$ ). This was done according to Hookes Law ${ }^{18}$ as follows:

Consider the strains in the 3D situation;

$$
\varepsilon_{1}^{3 D}=\frac{1}{E}\left[\sigma_{1}^{3 D}-\gamma\left(\sigma_{2}^{3 D}+\sigma_{3}^{3 D}\right)\right]
$$

$$
\varepsilon_{2}{ }^{3 D}=\frac{1}{E}\left[\sigma_{2}^{3 D}-\gamma\left(\sigma_{1}^{3 D}+\sigma_{3}^{3 D}\right)\right]
$$

Consider the strains in the 2D situation;

$$
\varepsilon_{1}^{2 D}=\frac{1}{E}\left[\sigma_{1}^{2 D}-\gamma\left(\sigma_{2}^{2 D}\right)\right]
$$




$$
\varepsilon_{2}^{2 D}=\frac{1}{E}\left[\sigma_{2}^{2 D}-\gamma\left(\sigma_{1}^{2 D}\right)\right]
$$

Since this is a reduction of the three dimensional stress state to a biaxial stress state, in both cases strains should be equal. i.e. $\varepsilon_{1}{ }^{3 D}=\varepsilon_{1}{ }^{2 D}$ and $\varepsilon_{2}{ }^{3 D}=\varepsilon_{2}{ }^{2 D}$

Therefore,

$$
\begin{aligned}
& \sigma_{1}^{2 D}=\sigma_{2}^{3 D}-\sigma_{3}^{3 D}\left(\frac{\gamma}{1-\gamma}\right) \\
& \sigma_{2}^{2 D}=\sigma_{1}^{3 D}-\sigma_{3}^{3 D}\left(\frac{\gamma}{1-\gamma}\right)
\end{aligned}
$$

Using the computed biaxial principal stresses and failure criteria described, the possibility of cracking and their directions (considered as perpendicular to the maximum principal stress) were identified.

\section{RESULTS AND DISCUSSION}

A summary of the observations from most of the buildings surveyed is shown in Table 3. Considering all cases, some common phenomena in the formation of these thermal cracks were identified. It was observed that cracks have formed on both internal and external walls, with the thicknesses of the cracks varying diurnally. Cracks have re-appeared after repair. In some buildings, cracking was pronounced in the long way direction wall; such buildings had overall aspect ratios of 2 or above.

The formation of cracks and their orientation have a direct relation to structural form and length of wall. For example, horizontal cracks were observed under beams in concrete framed walls at the centre of wall panels (Figure 6), but the cracks in load bearing walls were vertical in most cases (Figure 7). Downward inclinations of diagonal cracks are particularly pronounced near the perimeter for both concrete framed (Figure 8) and load bearing walls (Figure 9). Inclinations of these cracks to the horizontal were around $45^{\circ}$ and $55^{\circ}$, for concrete framed walls and load bearing walls respectively.

Using the principal stresses obtained from the finite element modelling, the possibility of cracking was identified and the summary of the results are shown in Table 4. The furthest stress point which is outside the failure envelope is considered as the starting point of a crack.
In the load bearing walls, stresses generated in masonry are enough to generate cracking. When the wall is short (M1), the maximum stress point is at the centre of wall (stress point is outside of the $\mathrm{S}_{3}$ region of failure envelope (Figure 5) and direction of major principal stress is almost horizontal. Therefore, formation of a vertical crack is possible at the centre of the wall. When the wall is long (M3 \& M6) the maximum stressed point is outside of the $\mathrm{S}_{2}$ region of the failure envelope (Figure 5) and the direction of major principal stress is around $25^{\circ}$ to the horizontal. The locations of points are close to the perimeter of the wall. Therefore formation of a downward inclined diagonal crack ( $65^{\circ}$ to the horizontal) is possible close to the perimeter. Developing of principal stresses and their directions in an element of load bearing masonry wall can be explained by the Mohr circle in Figure 10, which indicates that the direction of major principal stress is less than $45^{\circ}$ to the horizontal.

However, in the models $\mathrm{M}_{1}, \mathrm{M}_{3}$ and $\mathrm{M}_{6}$, the stresses developed in the interface link elements have not reached the failure requirement of the interface (Figure 4) and hence cracking at the wall-slab interface is not possible.

In the concrete framed walls, regardless of wall length and spans, link stresses have exceeded the failure requirement of the interface (Figure 4). Therefore, horizontal cracking is possible at the wall-beam interface. In the single panel walls, when the wall length is short $\left(\mathrm{M}_{2}\right)$, stresses developed in masonry are not enough to create cracks in it. However, when the wall length is long $\left(\mathrm{M}_{4}\right)$, a band of higher tensile stress develops in the masonry wall along the concrete masonry interface. These stresses are inclined at $81^{\circ}$ to the horizontal, so that any cracking in the actual wall will also be approximately horizontal. When the wall has more than one span, in addition to the interface cracks, formation of downward inclined cracks towards the panel edge (stress point outside the S2 region in Figure 5) is possible. These cracks have inclinations of around $45^{\circ}$ to the horizontal plane; this can be explained as arising out of a masonry element in pure shear, given that the vertical load of the slab is being carried by the concrete frame.

These results clearly indicate the relationship of crack pattern to the structural form and the aspect ratio of wall. Also the results obtained from FEM are similar to the crack patterns obtained by the survey of buildings. Therefore, we can say that the effects of thermal movements of an overlying slab on a masonry wall have been reasonably simulated by the finite element model. Hence, we can use FEM to model more complex geometric configurations. 
Table 3: Summery of building survey

\begin{tabular}{|c|c|c|c|c|c|c|c|c|c|c|c|c|c|c|}
\hline Building & $\mathrm{P} 1$ & $\mathrm{P} 2$ & P3 & $\mathrm{P} 4$ & P5 & P6 & $\mathrm{P} 7$ & P8 & P9 & $\mathrm{P} 10$ & $\mathrm{P} 11$ & $\mathrm{P} 12$ & P13 & P14 \\
\hline Load bearing & $\mathrm{Y}$ & & & & & & & & & $\mathrm{Y}$ & & & & $\mathrm{Y}$ \\
\hline Concrete framed & $\mathrm{Y}$ & $\mathrm{Y}$ & $\mathrm{Y}$ & $\mathrm{Y}$ & $\mathrm{Y}$ & $\mathrm{Y}$ & $\mathrm{Y}$ & $\mathrm{Y}$ & $\mathrm{Y}$ & & $\mathrm{Y}$ & $\mathrm{Y}$ & $\mathrm{Y}$ & Y \\
\hline Aspect ratio & 2 & 1 & 2.3 & 1.6 & 1.5 & 2 & 2 & 1.3 & 2 & 1.2 & 2.4 & 2 & 2 & 1.3 \\
\hline Most cracks on long way $(>75 \%)$ & $\mathrm{Y}$ & & $\mathrm{Y}$ & & & & & & $\mathrm{Y}$ & & $\mathrm{Y}$ & & & \\
\hline Cracks on both ways & & & Y & $\mathrm{Y}$ & Y & $\mathrm{Y}$ & Y & $\mathrm{Y}$ & & $\mathrm{Y}$ & & $\mathrm{Y}$ & Y & Y \\
\hline Thickness of the cracks varying diurnally & $\mathrm{Y}$ & $\mathrm{Y}$ & Y & $\mathrm{Y}$ & $\mathrm{Y}$ & $\mathrm{Y}$ & $\mathrm{Y}$ & $\mathrm{Y}$ & $\mathrm{Y}$ & Y & $\mathrm{Y}$ & $\mathrm{Y}$ & $\mathrm{Y}$ & Y \\
\hline Cracks have re-appeared after repairing & $\mathrm{Y}$ & $\mathrm{Y}$ & $\mathrm{Y}$ & $\mathrm{Y}$ & $\mathrm{Y}$ & $\mathrm{Y}$ & $\mathrm{Y}$ & $\mathrm{Y}$ & $\mathrm{Y}$ & $\mathrm{Y}$ & $\mathrm{Y}$ & $\mathrm{Y}$ & $\mathrm{Y}$ & $\mathrm{Y}$ \\
\hline Horizontal cracks under beam & $\mathrm{Y}$ & $\mathrm{Y}$ & $\mathrm{Y}$ & $\mathrm{Y}$ & $\mathrm{Y}$ & $\mathrm{Y}$ & $\mathrm{Y}$ & $\mathrm{Y}$ & $\mathrm{Y}$ & & Y & $\mathrm{Y}$ & Y & $\mathrm{Y}$ \\
\hline Horizontal cracks at wall slab interface & & & $\mathrm{Y}$ & $\mathrm{Y}$ & $\mathrm{Y}$ & & & & $\mathrm{Y}$ & & Y & & $\mathrm{Y}$ & \\
\hline Vertical cracks at column wall interface & & & $\mathrm{Y}$ & $\mathrm{Y}$ & $\mathrm{Y}$ & & & & $\mathrm{Y}$ & & Y & & $\mathrm{Y}$ & \\
\hline Vertical cracks in the walls & $\mathrm{Y}$ & & & & & & & $\mathrm{Y}$ & $\mathrm{Y}$ & Y & & & & \\
\hline Diagonal cracks near perimeter & $\mathrm{Y}$ & $\mathrm{Y}$ & Y & Y & $\mathrm{Y}$ & $\mathrm{Y}$ & $\mathrm{Y}$ & $\mathrm{Y}$ & Y & $\mathrm{Y}$ & $\mathrm{Y}$ & $\mathrm{Y}$ & $\mathrm{Y}$ & Y \\
\hline Diagonal cracks away from perimeter near columns & & $\mathrm{Y}$ & $\mathrm{Y}$ & $\mathrm{Y}$ & Y & & $\mathrm{Y}$ & $\mathrm{Y}$ & Y & & & $\mathrm{Y}$ & $\mathrm{Y}$ & \\
\hline Inclination of diagonal cracks to vertical & $\begin{array}{c}50- \\
60\end{array}$ & $\begin{array}{c}40- \\
50\end{array}$ & $\begin{array}{c}40- \\
50\end{array}$ & $\begin{array}{c}40- \\
50\end{array}$ & $\begin{array}{c}40- \\
50\end{array}$ & $\begin{array}{c}40- \\
50\end{array}$ & $\begin{array}{c}40- \\
50\end{array}$ & $\begin{array}{c}40- \\
50\end{array}$ & $\begin{array}{c}40- \\
50\end{array}$ & $\begin{array}{c}50- \\
60\end{array}$ & $\begin{array}{c}40- \\
50\end{array}$ & $\begin{array}{c}40- \\
50\end{array}$ & $\begin{array}{c}40- \\
50\end{array}$ & $\begin{array}{c}50- \\
60\end{array}$ \\
\hline Diagonal cracks at top of openings & $\mathrm{Y}$ & $\mathrm{Y}$ & $\mathrm{Y}$ & $\mathrm{Y}$ & $\mathrm{Y}$ & & & Y & & $\mathrm{Y}$ & & & & Y \\
\hline Cracks beneath windows & & $\mathrm{Y}$ & $\mathrm{Y}$ & $\mathrm{Y}$ & & & Y & Y & Y & $\mathrm{Y}$ & & & & $\mathrm{Y}$ \\
\hline
\end{tabular}

Table 4: Summary of results of numerical modelling

\begin{tabular}{|c|c|c|c|c|c|c|c|c|}
\hline \multirow[t]{2}{*}{ Model } & \multirow[t]{2}{*}{ Description } & \multicolumn{3}{|c|}{ Masonry stresses } & \multicolumn{3}{|c|}{ Interface link element stresses } & \multirow{2}{*}{$\begin{array}{l}\text { Probable pattern } \\
\text { of cracking }\end{array}$} \\
\hline & & $\begin{array}{c}\text { Maximum } \\
\text { prin. stress } \\
\mathrm{N} / \mathrm{mm}^{2}\end{array}$ & $\begin{array}{c}\text { Direction to } \\
\text { horizontal }\end{array}$ & $\begin{array}{l}\text { Location } \\
\text { (from outer } \\
\text { edge) } \mathrm{m}\end{array}$ & $\begin{array}{c}\text { Maximum } \\
\text { link normal } \\
\text { stress } \\
\mathrm{N} / \mathrm{mm}^{2}\end{array}$ & $\begin{array}{c}\text { Maximum } \\
\text { link shear } \\
\text { stress } \\
\mathrm{N} / \mathrm{mm}^{2}\end{array}$ & $\begin{array}{l}\text { Critical } \\
\text { location } \\
\text { (from outer } \\
\text { edge) } \mathrm{m}\end{array}$ & \\
\hline M1 & $\begin{array}{l}3 \mathrm{~m} \text { load } \\
\text { bearing }\end{array}$ & 0.19 & $2^{0}$ & 1.500 & 0.13 & 0.07 & 1.000 & 1 \\
\hline M2 & $\begin{array}{l}3 \text { m frame } \\
\text { columns @3 m }\end{array}$ & 0.15 & $45^{0}$ & 0.750 & 0.15 & 0.19 & 0.250 & \\
\hline M3 & $\begin{array}{l}6 \mathrm{~m} \text { load } \\
\text { bearing }\end{array}$ & 0.22 & $24^{0}$ & 1.250 & 0.07 & 0.05 & 1.000 & \\
\hline M4 & $\begin{array}{l}6 \mathrm{~m} \text { frame } \\
\text { columns @6m }\end{array}$ & 0.42 & $81^{0}$ & 0.125 & 0.14 & 0.38 & 0.500 & \\
\hline M5 & $\begin{array}{l}6 \mathrm{~m} \text { frame } \\
\text { columns@3 m }\end{array}$ & 0.23 & $41^{0}$ & 0.875 & 0.14 & 0.12 & 0.375 & \\
\hline M6 & $\begin{array}{l}9 \mathrm{~m} \text { load } \\
\text { bearing }\end{array}$ & 0.24 & $28^{0}$ & 1.375 & 0.08 & 0.10 & 1.000 & $T$ \\
\hline M7 & $\begin{array}{l}9 \mathrm{~m} \text { frame } \\
\text { columns @3 m }\end{array}$ & 0.29 & $46^{0}$ & 0.875 & 0.19 & 0.13 & 0.250 & \\
\hline M8 & $\begin{array}{l}9 \mathrm{~m} \text { frame } \\
\text { columns@4.5 m }\end{array}$ & 0.27 & $40^{\circ}$ & 1.300 & 0.26 & 0.05 & 0.250 & \\
\hline
\end{tabular}




\section{CONCLUSION}

(1) Numerical modelling is able to reproduce the phenomena observed in buildings where masonry walls are subjected to thermal movements of an overlying slab.

(2) The type and location of cracking depend significantly on whether the wall is load bearing or framed by reinforced concrete elements.

(3) Both types of arrangements give diagonal cracking near the ends of walls, although the crack orientation is steeper in load bearing walls.

(4) The survey also indicated that more cracking is formed in walls oriented in the long way direction of the building.

\section{Acknowledgement}

Advice given by Dr Manoja Weerasinghe is gratefully acknowledged. The financial support given by the National Science Foundation of Sri Lanka is also acknowledged.

\section{References}

1. Bicanic N., Stirling C.\& Pearce C.J. (2002). Discontinuous modelling of structural masonry. Fifth World Congress on Computational Mechanics, Viana, Australia.

2. Eng W. \& Shrive N.G. (1991). Finite element analysis of thermal stresses in diaphragm walls. In: Computer Methods in Structural Masonry (Eds. J. Middleton \& G.N.Pande). pp. 114 -123. Books and Journals International Ltd., UK.

3. Rots J.G. (1997). Numerical models in Diana. In : Structural Masonry - an Experimental/Numerical Basis for Practical Design Rules (Ed. J.G. Rots). pp. 46-95. A.A. Balkem Publishers, Rotterdam, Netherlands.

4. Lourenco P.B. (1998). Sensitivity analysis of masonry structures. Proceedings of the $8^{\text {th }}$ Canadian Masonry Symposium, Jasper, Canada.

5. Ibraham K.S. \& Suter G.T. (1990). Finite element study of thermal stresses in low-rise concrete masonry walls. Proceedings of the $5^{\text {th }}$ North American Masonry Conference, University of Illnois, Urbana-Champaign, USA.
6. Middleton J., Pande G.N. \& Loung J.V. (1991). Some recent advances in computer methods in structural masonry. In: Computer Methods in Structural Masonry. (Eds: J. Middleton \& G.N. Pande). pp. 1-21. Books \& Journals International Ltd., UK.

7. Berto L., Scotta R., Vitaliani R.V. \& Seatta A.V. (2001). An orthotropic damage model for non linear masonry wall analysis-irreversible strain and friction affects. Proceedings of the 3rd International Seminar on Structural Analysis of Historical Construction, Italy.

8. Martini K. (1997). Finite element studies in the out-ofplane failure of unreinforced masonry. Proceedings of the $7^{\text {th }}$ International Conference on Computing in Civil and Building Engineering, Seoul, South Korea.

9. Song Y. \& Kawalkani H. (2002). Three-dimensional rigid body analysis and simulation with viscoelastic binders. EJGE papers, www.ejge.com. Accessed on

10. NW-IALAS. (2006). Constitutive models for joints/ interfaces, integrity assessment of large concrete dam, www.nw-ialad.uibk.ac.at. Accessed on

11. Tzamtzis A.D. (2003). Finite element modelling of cracks and joints in discontinuous structural systems. Proceedings of the $16^{\text {th }}$ ASCE Engineering Mechanics Conference, University of Washington, Missouri, USA.

12. Hendry A.W. (1990). Structural masonry. Macmillan Press, Haundmills.

13. Samarasinghe W. (1980). The in-plane failure of brickwork. PhD Thesis, University of Edinburgh, UK.

14. Page A.W. (1980). An experimental investigation of the biaxial strength of masonry. Proceedings of the $6^{\text {th }}$ International Brick Masonry Conference, Rome.

15. Ayalaya D.F.A. (1998). Numerical modelling of masonry structures reinforced or repaired. Computer Methods in Structural Masonry 4: 161-168.

16. Syrmakezis C.A. \& P.G. (2001). Masonry failure criterion under biaxial stress state. Journal of Materials in Civil Engineering 13 (1):58-64.

17. Jayasinghe M.T.R. (1997). Load Bearing Brickwork Construction for Sri Lanka. STRAD Consultants (Pvt) Ltd Colombo.

18. Syrmakezis C.A., Antonopoulos A.K. \& Mavruli O.A. (2005). Analysis of historical masonry structures using three dimensional solid elements. Proceedings of the $10^{\text {th }}$ International Conference on Civil, Structural and Environmental Engineering Computing. (Ed. B.H.V. Topping) Paper 189, Civil-Comp Press, Stirling, Scotland. 